\section{The Personal Experiences Of The Regimental Aid Post. 1st Bn The Royal Regiment Of Fusiliers. OP TELIC, IRAQ}

\author{
S Edgar
}

The personnel of the RAP are a diverse group: soldiers, medics and the Padre, as well as evacuation ambulances from 1 Close Support Medical Regiment (CSMR) with young inexperienced crews.

Training during peacetime for the war role has been put sternly to the test during this operation. We were, from the very start, among the furthest forward elements of the Battle Group, often hurtling forward into areas of contact to treat casualties with incoming fire still ongoing. The threat on the battlefield was in all directions, possible NBC casualties weighed heavy on our minds and the reports of enemy targeting the red cross on thinly armoured 432 ambulances with rocket propelled grenades heightened the tension during manoeuvres.

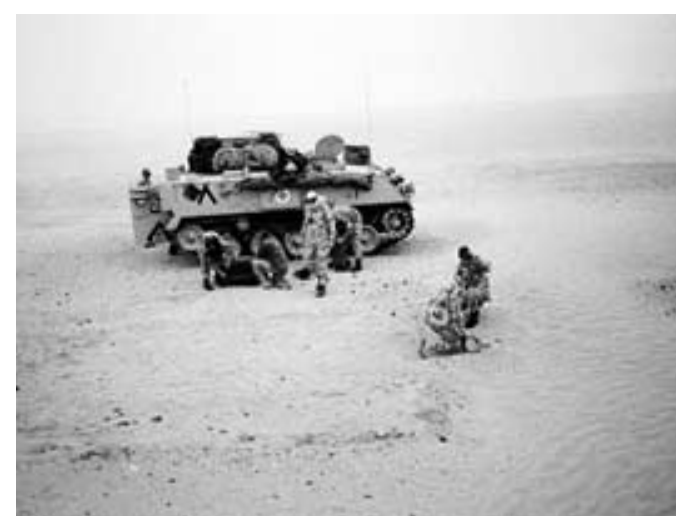

Fig 1. The RAP setting up in the desert.

I asked my team to record, in their own words, an event which has made an impression on them in the hope that this will provide some insight into the differing roles that make up the front line medical facility of an armoured battle group. We were involved in many fraught situations and their actions were at all times exemplary.

It was clear that all evacuation from the front line would be by armour and wheels, not helicopters as had been originally suggested. Anti tank mines lay by the sides of the roads and made two-directional traffic a constant challenge. In a change to the med plan enforced by circumstance, the pattern emerged that the RAP would be called forward to wherever there were casualties, to treat on site and prove the route for evacuation. This was only sustainable as the actual volume of casualties at any one time was low and the armoured medical section (AMS) from 1 CSMR were in reserve further to the rear.

On the first morning after the war started we were in a farm complex waiting to be called across the border.

"As the battle group started to cross the berm obstacle our call sign was called forward to a civoy casualty who sustained a gun shot wound to the head. This civilian was taken away in a civilian vehicle before we could arrive at the scene. The next were three civilians crossing into our area who had sustained injuries including gunshot wounds to the leg and an injured hand. I was involved with the treatment of gunshot wound to the leg."

LCpl Priest age 29 1RRF 432 comd RMA 2

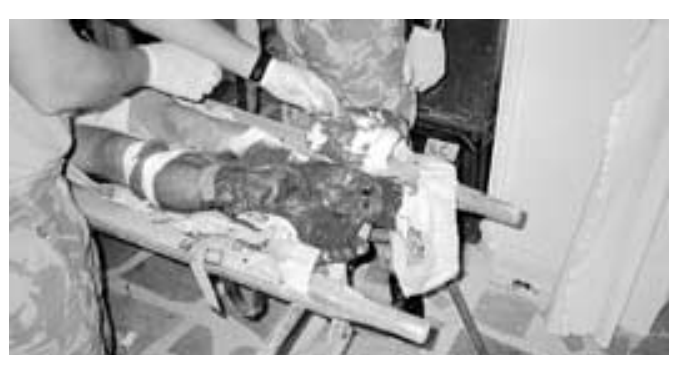

Fig 2. A foot injury.

"On the date in question when we got through the berm we got to a little hamlet where we stopped for 20 mins then suddenly we got two children with severe wounds to their legs and one had her hand disfigured. So being an RMA 3 I took it on myself to try and help the children but I was restricted by my medical training, but did what I could to help them to live. When one started to cry I thought to myself this isn't right that children are getting caught up in this liberation campaign."

Fus Thompson age 20 1RRF 432 driver RMA 3

The two teenage civilian girls had, it transpired, been hit by a helicopter gunship strike. One had severe blast injuries to the medial aspect of her right leg extending up to her pelvic area, she was becoming less responsive and more shut down. We tasked one of the warrior vehicles to request helivac and proceeded to stabilize the girls as best we could. 15 family members and locals, who were understandably anxious, surrounded them. The second girl had a traumatic amputation of her left hand and some fingers from her right hand were missing. She had
Trenchard Barracks, Celle, BFPO 23. 
also sustained an open femoral fracture, which had been splinted by the Sqn Medic. When the helicopter arrived they were surprised to find that the casualties were civilian, we insisted they take them as there was no time for lengthy discussion. I had no idea where they were going and took what details I could from the locals, in Arabic, in the hope that someone, somewhere may be able to find them and get them back to their families once treated. I have heard nothing of them since.

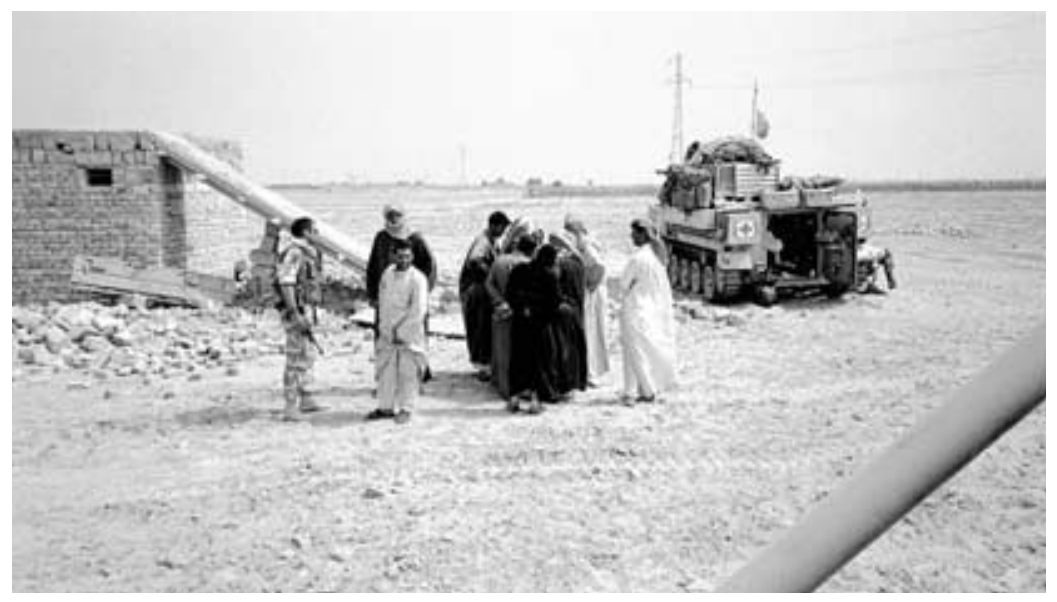

Fig 3. Taking details from the relatives of the girls hit by the helicopter strike.

The push north continued the following day and we remained attached to $\mathrm{Y} / \mathrm{B}$ Coy/Sqn group.

"Well I'm LCpl Ali, I'm the driver of a 432 track wagon and I'm driving for the RAP on the tour of Iraq. The driving is pretty hectic at times. One time is when we were on the way to take Basra airport. The lights were off and it was pitch black and we were behind the company that got tasked to takeover the airport. All I could think about was what was waiting for us there. When we did arrive all was well. Most of the time, when you are driving, in the back of your mind is that if this wagon gets a hit it would not withstand it.

I've most probably seen more blood and guts than most of the lads over here being an amby driver, but you put it all behind you.

My worst nightmare is seeing someone who I know but luckily it hasn't come to that for me."

The Armoured Evacuation ambulances from 1 CSMR were attached to the other forward call signs for evacuation to the RAP/AMS once again near the thick of the fighting.

"One memory I have that is still quite clear occurred whilst attached to C Sqn QRL. It was the second night of being in Iraq, so things were quite tense. We had moved forward to take over bridge 4, as the Challengers moved forward we held back to hold the med support.

From where we were, you could see the firefight, tracer rounds and Artillery going down, just a few kilometers away. Whilst I was sleeping
I heard someone shouting and my heart near jumped up my chest, I didn't know what was going on, the infantry boys attached had come under contact, 30 enemy to their section of 8. So there was a major need for support to prevent casualties. That was the start of the night, within the next few hours we were in dress cats $R 1,2$, 3 , and 4 having had a suspected nerve agent attack, but seeing the POWs smoking their cigarettes confirmed the fact that it was safe to unmask.

Fust as everything felt like it was going back to normal we were fired upon in the middle of a replen. The enemy's whereabouts wasn't clear then he was sighted and fire was put down on his position. And after what seemed like hours the enemy was captured, however during this commotion an unsuspecting farmer trundled along on his bright red tractor from the area of the enemy. The Sqn let loose its arsenal on $\mathrm{Mr}$ farmer who managed to escape at $10 \mathrm{mph}$ unscathed which I was thankful for."

Pte Moss age 201 CSMR 432 driver

The NBC threat was high and we were then in dress cat 4 through the night, with occasional incoming artillery and mortars necessitating 'masking up' until the splashdown area was established. That morning we had a report of a chemical casualty on route to our location.

"Being fairly clued up NBC wise I volunteered/ was tasked to move further down the road with a CAM in full IPE in readiness to 'sniff' our possible cas. It was a most strange feeling stood like a lemon with a CAM in hand feeling very apprehensive waiting for an ambulance to rock up. When it did turn up, I waved it down and ran forward to check the cas, upon opening up the back I saw the cas on a stretcher and to my horror the medic in the back unmasked. Thinking he must be some lunatic on day release and that we would have to treat him too, I sniffed (with the CAM) the casualty, got nothing, tried again, nothing. So I took the plunge and unmasked, myself and the crew, then directed them forward to the MO (who treated him for a completely different condition).

This wasn't the last time I had to carry out the task, at least one other occasion I had to repeat the whole drill. (And it still wasn't any easier.)"

LCpl Cummings 1 RRF RMA 2

The casualty had passed out and vomited whilst wearing his respirator. Having been told that they had been gassed, someone had administered a combopen of atropine, pralidoxime and diazepam, the medic on scene administered a second combopen and brought him back to our location. The double dose of diazepam did little to help him come round but hindsight was unavailable at the time. A BM of 1 showed the way and he improved dramatically with the IV glucose, he recovered in hospital for a couple of days before returning to duty. The 
NBC threat was real enough to everybody at the time to keep us on edge.

As the Battle Group consolidated on their respective bridges to the west of Basra, HQ moved up into the Airport. We moved down to the 'cloverleaf' 1500 metres from bridge 2, a site that was being intermittently mortared as, alternately, warriors then challenger $2 \mathrm{~s}$ probed forward to harass the enemy. It was not long before the first of the two lowest points came for the Battle Group and us.

"A message came over the radio that one of our Challenger 2 tanks had been taken out by RPG and that there had been 2 casualties. Something didn't seem to click, I couldn't see an RPG taking out our best tank. CSgt Flannagan was on the net constantly on the way to the casualties gaining as much information for us as poss. It wasn't until we pulled up that we found out it was a blue on blue. From another tank 2 rounds of high explosive had left 2 dead and 2 injured. As we pulled up I grabbed my crash kit and bomb-bursted out of the 432 followed by LCPl Cummings. As I approached the scene 2 figures were lying on the ground. Cpl Naz came over and briefed me up on the cas. The Doc and Cpl Crooks appeared on the scene. The Doc took the seriously burnt casualty, all that went through my mind was he's no older than 19 and he may die. Myself and Cpl Crooks set upon the 2nd casualty. He was in severe pain I gave him his second morphine whilst Cpl Crooks took his obs. I drew up antibiotics and administered to both casualties, it's the first time I've seen such bad burns.

The Doc shifted to our cas and we prepared him for evacuation. The poor bloke was in a lot of pain.

I was well aware of the anger and frustration of the other tank crews, they had been told that another one of their tanks had done this damage. The wheeled ambys turned up and we loaded them on. The yanks let us down again not providing helivac. Later I read in the paper that one of the fatalities had left behind a wife and kids. The death of a British soldier leaves us feeling empty. I always find myself thinking, what if that had been me."

\section{Cpl Stockwell RAMC 1RRF RAP}

Our aim in the RAP is to assess, stabilize and package casualties for speedy evacuation, there is no time for a complete investigation of all possible injuries so I do not know the true extent of these boys' wounds. I hope they are doing well. The waste of some lives and the ruination of others through blue on blue incidents is difficult to deal with. The fog of war obscures the complete picture of what happened. Those on the ground find out only by piecemeal and by rumour the circumstances involved. All the procedures and equipment are in place to prevent it happening but it still occurs. There is no solace.

We returned to the bridge and began to alternate roles with the AMS. The heat, flies and tedium of waiting for days on end at the more frontline bridge position was gratefully interspersed with a couple of days of washing clothes, playing cards, admin and sick parades in the airport. On Sunday 6th April, I attended the morning briefing and we were given our $\mathrm{H}$ hour to move into Basra itself. We were once again in convoy with Y Coy on the way in, when we had reports of a casualty in severe difficulties further forward. We moved as fast as possible up to his location.

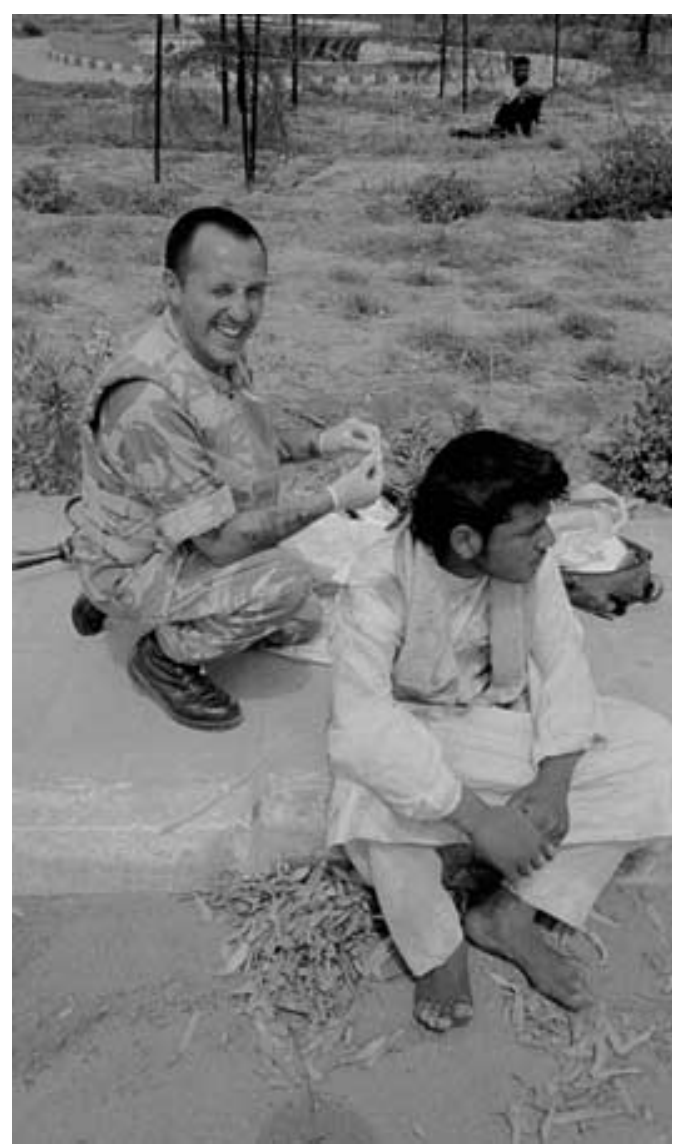

Fig 4. LCpl Priest administering to a POW in Basra.

"On the advance to Basra we were called to an incident where a Fusilier was hit near the Power station but by the time we got there his coy medic was there so the doctor crashed out with ourselves to give the lad hope so we tried to save him under a mortar attack but it was too late. Then I thought to myself we couldn't do enough but in reality we tried everything to save one of our Fusiliers. It's like losing a brother, these are events that will stay with me for ever."

Fus Thompson

We completed the move to our Battle Group objectives, it seemed a hollow victory at already too great a cost to all. But casualties continued and we, like the rest of the Battle Group, carried on. Intermittent firefights between looters and occasionally with our forces injured more. There is little more soul destroying for me or my medics than seeing injuries where we can do nothing, being on scene so quickly increases the likelihood of this occurring. 
"Another time, we (14C with the Doc) were tasked to go to $Y$ Coy who had a civvy cas. We jumped in the ambulance and shot off, it took about 10 minutes to get there. Myself and Cpl Stockwell had our kit prepped so we weren't unduly worried. Upon arriving at the location we de-bussed next to Y Coy's ambulance and went forward to a local shack where we found LCpl Lee White knelt down next to a youngish woman holding an FFD on her head. I came around, knelt next to him and asked what I could do, he told me to check the kids next door. By this time Capt Edgar was having a quick look at the wound with Cpl Stockwell. The woman had a large head wound, which brain matter was leaking out of. After looking myself I went to check the kids (who were terrified - obviously) I attempted to reassure them, then moved back to help load the woman onto a stretcher and into the ambulance. Her breathing had already begun to deteriorate. We got sorted and then drove as fast as possible to the hospital-unfortunately the doctors did not rate her chances very much."

\section{LCpl Cummings}

She had been shot through the head and was clearly a P4 hold casualty, meaning that she had sustained an unsurvivable injury but was not yet dead. We took her to the local hospital in one ambulance and took her children in another. There had been a firefight involving grenades and a shack was on fire next to theirs so they could not stay there. There was a large crowd at the casualty department, who were very matter of fact about the whole thing and took the children away, thanking us for bringing them. I didn't feel we deserved their thanks.

"We had a casualty, supposedly militia, brought in from $Y$ coy. It looked like he had picked something up and it had blown up on him. There were traumatic amputations of both of his hands and an abdominal wound through which part of his liver was hanging out. He was voice responsive but deteriorating and was well shut down. The Doc and I tried cannulating him but failed, Doc then tried a cut down with no luck and eventually succeeded with femoral access. We stabilized him and evacuated to the DS. The emergency treatment of these people is exactly the same as for our soldiers but the mind-set on whether they make it or not affects us a bit different."

\section{Cpl Garry Crooks RAMC CMT1}

We had taken over part of a hotel as the RAP and were based there with an evac ambulance as the RPG threat was still present. Efforts were ongoing to fortify the location and to prevent the looting from cascading any further out of control. In addition to this a wave of gastro-intestinal upset was spreading through the unit, putting people out of action for $24 \mathrm{hr}$ periods, which had to be spent close to the latrines.
Occasional casualties were being evacuated to the DS 1a or $34 \mathrm{Fd}$ Hospital during which the following incident occurred.

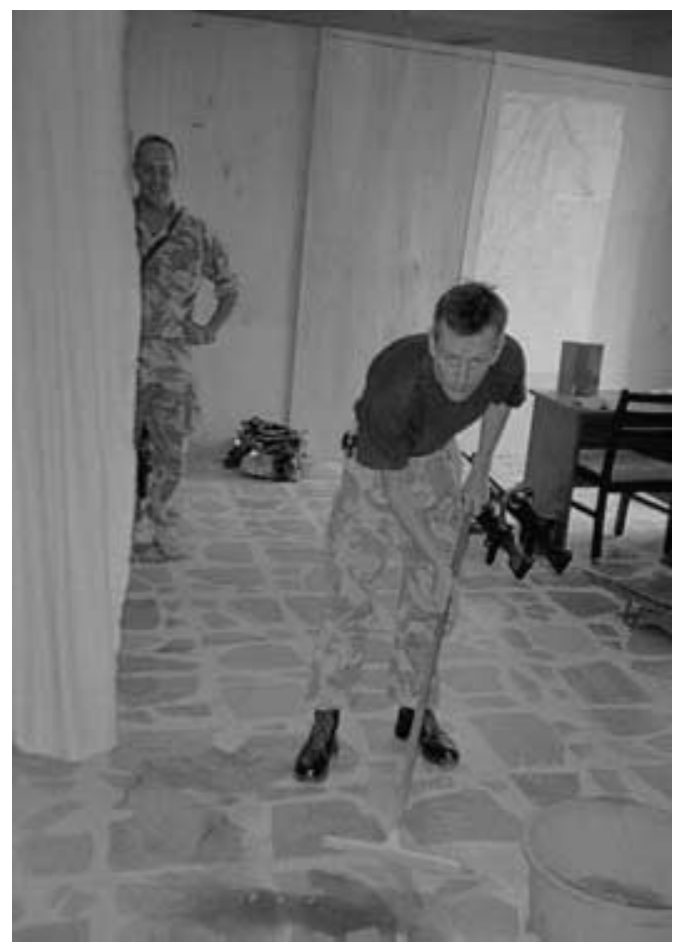

Fig 5. The Padre clearing up after a trauma case.

"Thinking back now something that is scorched into my memory since arriving in Iraq, was what started as a quiet day transporting a P3 casualty to the DS, a straightforward procedure. On route we came across a mass of people surrounding a car and blocking our way. fudging by their expressions they were clearly very distressed, one person in particular. Once on the scene I could make out this limp looking figure of an 8yr old boy motionless on the bonnet on a rusty old car, he'd been shot in the abdomen. This tasking from nowhere with the sheer amount of people fuelled by confusion and helplessness was not an easy one. From the word go my crew were outstanding considering their age and experience the oldest being about 20, they never needed prompting or direction of any kind and carried out their roles what was required of them from soldier to driver to humanitarian"

Cpl Nazar 1CSMR 432 comd. Evac ambulance

"We had just come from the dressing station which was set up at BIA. As soon as we returned to the RAP we took a P3 casualty back to the DS. It must have been about 5 minutes into the drive and we were just coming up to the bridge. We were stopped by the QRL shouting there is a young boy with a gunshot wound. I grabbed all the medical kit and headed towards a civoy car. I didn't know what to expect my mind was running everywhere.

This casualty was a P1 and needed to be transported to the DS straight away. It was a young boy I would say no more than 8 yrs old. His father was next to me screaming "help my 
son please help him." The little boy had already been given some basic treatment so we changed the fluid bag and got him away. By this time the sweat was pouring off me and my heart was going, it didn't help that the back of the 432 was like a steam room. It takes 30 minutes to get there but it felt about 2 hours.

At this stage the little boy wasn't looking too good. My p3 casualty was still in the back helping me with anything he could. Whilst his father was asking me the same question over and over again 'is he dead?' I tried my best to explain that we were almost there and his son would be seen by the doctor soon, watching my charades impression was the last thing on his mind so I gave up. Finally the DS was in sight, a thumbs up to his father that we were finally there brought relief to him and even more to myself.

The doctors and CMTs took the little boy through the tent and cracked on. I went outside and calmed myself down, it was a big shock to the system. Then I started thinking about what had just happened. I made the conclusion our crew gave $110 \%$ from the driver finding the route, the comdr controlling the situation and myself applying everything that I had learnt from training and in theatre to that little boy."

Pte Patton age 19 1CSMR CMT 2

The radio today said that Gulf War 2 was nearly over. I'm glad. Many Doctors and paramedical staff have been in front line fighting situations during this war, treating conditions they may never have encountered before. I hope this gives some insight into what we have done and serves as a lesson as to what we may encounter in the future. All involved have done their duty as required. I would think many forward medical teams have had similar experiences and I do not claim we are anything special, but these have been ours.

\section{Glossary}

1 CSMR; 1 Close Support Medical Regiment made up of $\mathrm{A} \& \mathrm{E}$, a small ward, a surgical facility, reenforcement doctor and medics forward teams and evacuation ambulances

CALLSIGN; radio call sign, used to talk in veiled speech on the radio.

RAP; Regimental Aid Post. 1 Dr, 2 paramedics \& drivers, infantry commander, padre.

NBC; Nuclear, Biological, Chemical.

432 AMBULANCE; 50 yr old thinly armoured vehicle with a fitting for 1 stretcher in the back.

RMA 3,2,1; regimental medical assistant- infantry soldier who has undergone medical paramedic training to a certain level. RMA 1 being fully qualified.

COY/SQN; COMPANY/ SQUADRON; subunit of the battle group, comprising around 150 men and 1215 tanks or armoured personnel carriers.

QRL; QUEENS ROYAL LANCERS “tankies”.

DRESS CATS; states of NBC threat from carrying suits and masks to fully dressed and all sealed in.

CAM; a handheld device to detect chemical weapons.

RPG; hand held anti tank missile.

DS; DRESSING STATION, part of 1CSMR, A\&E and a surgical facility. 